DIGITAL COMMONS
$@$ UNIVERSITY OF SOUTH FLORIDA

Volume 7

Issue 1 Volume 7.1 (Spring 2017)
ABO: Interactive Journal for

Women in the Arts, 1640-1830

2017

\title{
Embodying Character, Adapting Communication; or, the Senses and Sensibilities of Epistolarity and New Media in the Classroom
}

Jodi L. Wyett

Xavier University,wyett@xavier.edu

Follow this and additional works at: https://digitalcommons.usf.edu/abo

Part of the Educational Methods Commons, Feminist, Gender, and Sexuality Studies Commons, and the Literature in English, British Isles Commons

\section{Recommended Citation}

Wyett, Jodi L. (2017) "Embodying Character, Adapting Communication; or, the Senses and Sensibilities of Epistolarity and New Media in the Classroom," ABO: Interactive Journal for Women in the Arts, 1640-1830: Vol.7: Iss.1, Article 8. http://doi.org/10.5038/2157-7129.7.1.1139

Available at: https://digitalcommons.usf.edu/abo/vol7/iss1/8

This Pedagogy is brought to you for free and open access by Digital Commons @ University of South Florida. It has been accepted for inclusion in ABO: Interactive Journal for Women in the Arts, 1640-1830 by an authorized administrator of Digital Commons @ University of South Florida. For more information, please contact digitalcommons@usf.edu. 


\title{
Embodying Character, Adapting Communication; or, the Senses and Sensibilities of Epistolarity and New Media in the Classroom
}

\author{
Abstract \\ This essay describes a classroom role-playing activity that incorporates both modern social media and \\ the tools of eighteenth-century composition. Students communicate with each other as characters in the \\ assigned novel, by either texting, tweeting, or writing longhand with quill pens. The exercise aims to help \\ students grasp the sometimes-elusive historical contexts of eighteenth-century writing as well as the \\ ways in which we interpret and adapt those contexts and their attendant modes of communication when \\ we read for meaning in our own moment. My experiences suggest that the activity is particularly effective \\ at helping students to reflect upon their own interpretive choices and to understand how medium affects \\ content. Furthermore, it can illuminate the ways in which the medium influences not only the message, \\ but also the messenger, thus revealing potentially surprising connections between material modes of \\ communication, embodied behavior, and intellectual output.
}

\section{Keywords}

communication, pedagogy, eighteenth-century, women, gender, novel, Twitter, texting, epistolarity, roleplaying, character

\section{Creative Commons License}

(c) $($ ) $\odot$

This work is licensed under a Creative Commons Attribution-No Derivative Works 3.0 License. 


\section{Introduction to $\mathrm{ABO}$ 's Teaching Forum}

Cynthia Richards, Pedagogy Editor

This issue inaugurates the first of $A B O$ 's Teaching Forums. These forums feature a series of shorter essays that are in conversation with one another about issues related to teaching all aspects of women in the arts in the long eighteenth century. Geared to a scholarly audience, these forums may be both practical and theoretical in nature, but will uniformly take as their focus the public work of the classroom and how scholarship is translated into action. These first four essays illustrate that focus by foregrounding practices in which students are asked-sometimes quite literally - to embody knowledge of the eighteenth century, and particularly, how gender reframes that experience. As such, they speak to the long-standing feminist practice that acknowledges the role of the body in shaping experience and point to emerging insights in Body Studies, which focus on a history of the body and its representation.

Listed chronologically in terms of content, the four essays included in the forum are: "Arabella's Valentines and Literary Connections [dot] com: Playing with Eighteenth-century Gender Online" by Melanie Holm; "Less of the Heroine than the Woman': Parsing Gender in the British Novel" by Susan Carlile; "Embodying Gender and Class in Public Spaces through an Active Learning Activity: Out and About in the Eighteenth Century" by Ann Campbell; and "Embodying Character, Adapting communication; or, the Senses and Sensibilities of Epistolarity and New Media in the Classroom" by Jodi L. Wyett.

\section{Embodying Character, Adapting Communication: Making Sense of Epistolarity and New Media in the Classroom}

Jane Austen's first published novel, Sense and Sensibility (1811) is also the first book we discuss in my upper-level undergraduate English course, "Jane Austen: Then and Now." This class usually enrolls a broad constituency of students, yet even English majors with practice in literary explication rarely arrive with extensive prior knowledge of eighteenth-century Britain. Role-playing exercises that both enact the conditions of late eighteenth- and early nineteenth-century communication and revise or adapt them to our own setting can help students to engage with the sometimes elusive historical contexts of eighteenth-century writing as well as to understand the ways in which we interpret and adapt those contexts and their attendant modes of communication when we read for meaning in our own moment. As both Ann Campbell's and Melanie Holm's essays in this forum confirm (as do other $A B O$ pedagogy essays published by Caroline Breashears, Kathryn Strong Hansen, and Misty Krueger), role playing can address myriad questions that arise from communication issues apparent then, many of them 
specifically gendered, as well as shifts in meaning when we employ media in use now: Would Lucy Steele reveal more or less with a character limit and a broad Twitter audience? What would Mrs. Jennings do with a Twitter account? Would texts between Elinor and Marianne increase or decrease intimacy given how obliquely they communicate face-to-face? Would letters written then necessarily have been private? Are texts now? How do conventions for texting and tweeting now offer continuities with and differ from epistolary conventions then? What happens to your own discourse when you sit down to write a letter with a quill pen rather than thumbing brief messages into the electronic ether? While students need more solid grounding in the complexities of social codes in Austen's era, that last question reveals that a clearer sense of the material contexts surrounding communication in the period can also provide one small way to get at the embodied experiences of communication during the long eighteenth century.

I have developed a role-playing exercise that re-creates eighteenth-century epistolary communication and uses modern digital communication methods to foreground the relationship between medium and message. Furthermore, it illuminates the ways in which the medium can influence not only the message, but also the messenger, thus revealing potentially surprising connections between material modes of communication, embodied or physical behavior, and thought patterns or intellectual output. The activity, easily tailored to accommodate other novels, involves dividing the class into three groups (texters, tweeters, and letter writers) with students role-playing as characters from the novel who have some sort of communication issue or issues. Engaging with the tools of composition available during the Regency period - quill pens, ink, a candle, sealing wax, and a seal—as well as those commonly used now-cell phones, laptops, Twitter, and text messaging apps-students experience firsthand how different forms of communication produce different forms of meaning and, indeed, something of the reciprocity between the lived experience of the quality of life at a particular time and its forms of expression, artistic and otherwise. After the role-playing activity, students write individual reflections and share through large-group discussion to facilitate analytical and synthetic critical thinking. Beginning with an accessible focus on character, ultimately the exercise asks students to consider themes such as the social construction of gender and communication as well as the paths towardand away from - an idealized notion of solidarity between women in Sense and Sensibility.

While Austen's works seem more accessible than many eighteenth-century novels, Sense and Sensibility can be challenging to students for whom eighteenthcentury gendered social contexts and generic conventions clash with modern social codes and expectations based on social media and film (usually Pride and Prejudice adaptations). Gendered social customs - from bestowing a lock of hair as a symbol of affective ties to a woman riding alone with a gentleman in his carriage - are 
invested with great significance in the novel. While all of the essays in this forum share a common goal of helping a variety of students to recognize how social contexts are both reflected in and shaped by the novels we teach, many of my students are confounded in particular by the ways in which Austen's characters communicate with each other, or more often do not communicate with each other: Why doesn't Marianne tell Elinor she isn't engaged to Willoughby? Why doesn't Elinor tell Marianne Edward is engaged to Lucy Steele? Why does Lucy Steele so brazenly dissemble when she solicits Elinor's advice about her secret engagement? Why does Elinor keep Lucy's secret? Why can't a woman write a letter to a man who isn't her fiancé? Why is Mrs. Jennings' gossip mongering so painful to the Dashwood sisters? Why is Marianne scolded for just saying what she feels?

Generic expectations constitute another related source of confusion for students, who are usually unfamiliar with both the Gothic and sentimental novel conventions Austen employs and subverts in Sense and Sensibility and eighteenthcentury novelistic notions of heroism, as Susan Carlile's essay here demonstrates. Consequently, students often register surprise that Austen's novels lack the attributes of modern romance found in film adaptations. Swashbuckling masculine heroes who win the women they love by confidently proclaiming their feelings and initiating passionate embraces are conspicuously absent. Instead, Austen's heroes are often reticent; the narrator asks readers to fill in the extra-textual blanks while declarations of love are merely referenced rather than enacted in detail. Quite unromantically, Sense and Sensibility's Marianne Dashwood only learns to love her husband "in time" after being coaxed into a match initially encouraged by everyone but herself (379). Additionally, more than the genre's requisite heterosexual unions, Austen promotes the bond between the Dashwood sisters as the source of her happy ending. She employs her characteristic irony in the last line of the novel to suggest that sisterhood, defined both literally and in terms of social and political solidarity between women, could be a key source of happiness for women at a time when marriage was an uncertain if compulsory economic enterprise: “ . . among the merits and happiness of Elinor and Marianne, let it not be ranked as least considerable, that though sisters, and living almost within sight of each other, they could live without disagreement between themselves, or producing coolness between their husbands" (380). This final line emphasizing the bond between Elinor and Marianne rather than their respective marriages crystallizes when the novel is taken in part as an exploration of the barriers to communication and solidarity between women in Regency-era Britain.

This exercise requires students to role-play with a partner, communicating as characters from the novel and building on any scene or scenes in the novel by texting, tweeting, or writing letters. It works using sympathetic characters such as Elinor and Marianne or antagonistic characters such as Elinor and Lucy Steele. It can also be adapted to other novels: Pamela and Mrs. Jervis versus Pamela and Mrs. 
Jewkes, for instance. It could also work well with an epistolary novel. Students could take one of Evelina's letters to Mr. Villiars and re-write it as a letter to Miss Mirvan to consider how her discourse and the meaning of the novel might change with more communication between women. The exercise could even be used to put different novels in communication with each other, such as a scenario where Richardson's Pamela converses with Haywood's Syrena Tricksy. In all cases, students enter the text through one of their favorite portals, characterization, and come out in the end having more closely explored theme, particularly those themes related to gendered discourse.

The entire activity takes approximately one hour. See Appendix A for the handout I give to students. The steps for the activity are as follows:

1) Divide students into three roughly equal-sized groups of texters, tweeters, and letter writers. Let students choose based on their comfort level with the technology and willingness to expose themselves to online social media. During a previous class session, poll students regarding their ability to use Twitter for class purposes. Some students have good reasons to avoid social media, even if they create an account under an assumed persona, which Twitter allows. Tweeters should choose a hashtag so their conversation can be traced later.

2) For approximately $\mathbf{1 5 - 2 0}$ minutes, have students text, tweet, or hand write letters to a partner as characters in the novel who have some sort of communication issue with each other. I allow students to choose their own character combinations, especially since one group of three is often required. Most of my students choose Elinor and Marianne, but Lucy Steele and Mrs. Jennings are also popular choices for their comic potential. Though there is not enough time for the letter writers to write responses to each other, be sure they remember to deliver their letters.

3) After the initial period of writing in pairs or groups, give students 5-10 minutes to write a brief individual reflection from a prompt provided to consider purpose, audience, medium, and the themes of the novel they employed to complete the exercise. I provide the following prompt for students:

Consider the purpose of your communication, the audience, the medium or means by which you communicated, and the themes of the novel you think you brought to bear on this exercise. Some questions to ponder just to get you going include: Who is the intended audience for your given form of communication and is the intended audience always also the actual audience? Explain. Did your method of communication increase or decrease intimacy between the characters? Why or why not? Did it create obstacles or hostilities or build bridges? Why? How? Did the characters reveal more 
or less of themselves with your format and audience considerations? Explain. What happens to your discourse when you communicate in a method to which you are accustomed or unaccustomed, as the case may be? Do factors such as age, race, class, and gender affect your method of communication? Why or why not?

4) Finally, save at least $\mathbf{2 0 - 3 0}$ minutes of class time to discuss the activity as a large group, including reactions to using current technology versus attempts to recreate Regency historical conditions and conventions.

This exercise is designed as an introductory, ungraded in-class activity that allows students to engage personally with the course material in a low-stakes, entertaining format. It could easily be adapted to include graded content by establishing a course-specific hashtag on Twitter, requiring students to submit screen shots of texts and tweets as well as the handwritten letters, or even asking students to prepare their conversations as formal artifacts for online exhibition. In any case, a more substantial written reflective element or more advance preparatory time outside of class could help to turn this exercise into a more formal, graded assignment. (See my digital pedagogy LibGuide if you are looking for more robust assignment guidelines and rubrics for some common digital assignments.)

The objectives are stated on the assignment handout:

- To explore how different forms of written communication produce different forms of meaning.

- To understand characterization and theme, then create your own interpretation from that understanding.

- To analyze and reflect upon perspective, purpose, medium, and audience.

- To consider what it takes to be an effective and responsible communicator.

More specifically, this exercise seeks to help students find meaning, broadly speaking, in the novel by better understanding Austen's social contexts and by beginning the active work of interpreting her writing via adaptation. It thus serves as a microcosm of some of the overall course objectives, which include reading Austen's work closely for meaning, grasping the work within its original social contexts, and understanding why it continues to serve as the inspiration for a multitude of adaptations. The last objective often proves challenging for students who have difficulty analyzing their own cultural contexts. This observation is especially true given how adaptations are, as Robert Stam puts it, necessarily and complexly "caught up in the ongoing whirl of intertextual reference and transformation, of texts generating other texts in an endless process of recycling, transformation, and transmutation" (66). By writing letters, texts, or tweets in character, students create their own mini-adaptations of a sort, generically distinct 
from Austen's writing, that produce meanings both intimately tied to and independent of Austen's novel, exemplifying the way in which genre shapes meaning and how a similar story can communicate and embody a multitude of experiences determined by distinct contexts of production and consumption.

My anecdotal experiences with this activity suggest that it is particularly effective at helping students to reflect upon their own interpretive choices and to understand how medium affects content. In my most recent "Jane Austen: Then and Now" course, students drew on their knowledge and interpretation of the novel's characters to complete the activity and many suggested it heightened their appreciation of Austen's ability to create complexly rendered characters. Students who worked with modern modes of communication adapted their language and idioms accordingly. Texters used emojis, texting shorthand, and modern slang.

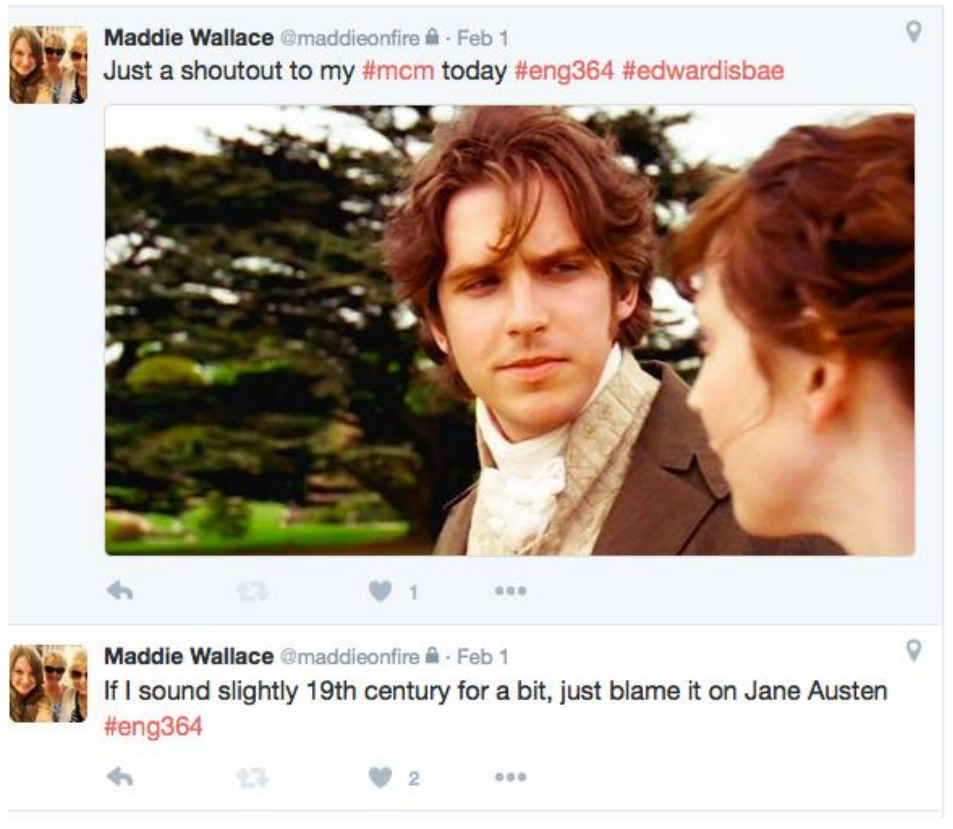
Tweeters not only used emojis, abbreviations, and slang, but also deployed memes, GIFs, and the distinct language of the Twitterverse. In the example below, for instance, \#mcm references "Man Crush Monday" (conveniently, the class met on Monday nights).

All of the students who texted or tweeted felt strongly that their conversations changed the nature of the relationships originally depicted by Austen, particularly expressing that they revealed much more of themselves to each other than Austen's characters would have. They believed the greater transparency arose not only because they were engaged in direct communication rather than experiencing those relationships through the lens of Austen's narration, but also because their modes of communication, grounded in our contemporary cultural norms, necessitated greater openness. I noted that all of the texting and tweeting students honed in on Austenian humor and irony while the letters written longhand were more emotionally earnest and plaintive, deploying none of the sarcasm or, at times, crude humor used by the students in the other groups. Instead, letter writers imitated Austen's language and writing style despite being given no direction to do so. The letter writers on the whole also expressed significantly more contemplative, thoughtful conclusions than their texting and tweeting classmates. Our comparative analysis during the full class discussion then addressed how discourse is not only a 
matter of diction, but is also strongly tied to social context and technological medium.

Though the texters and tweeters, at turns quietly mirthful and outright raucous, appeared to be enjoying themselves more thoroughly during the exercise, I should also note that they were envious of the students who worked diligently with the most mechanically

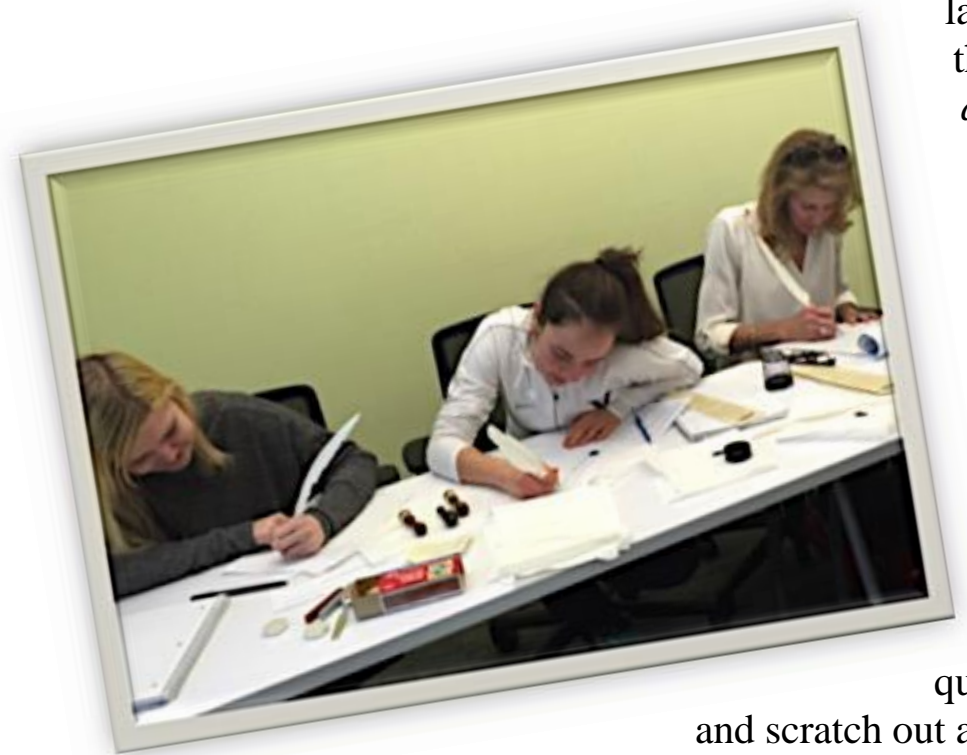
laborious instruments. After the large group discussion, all of the students wanted to try writing with a quill pen. (The class met for three hours in the evening, so everyone was able to write with the quills at the break.) Embodying the past, albeit only via crude approximation, proved seductive, compelling each of the students to pick up the quill, dip it in the ink well,

different material circumstances cause us to necessarily miss much of the meaning more readily available to readers in the long eighteenth century. Nevertheless, the writing still speaks to us, compelling us to rewrite and reenvision it in speech, writing, images, and most notably in actions, the stuff of effective, embodied pedagogy.

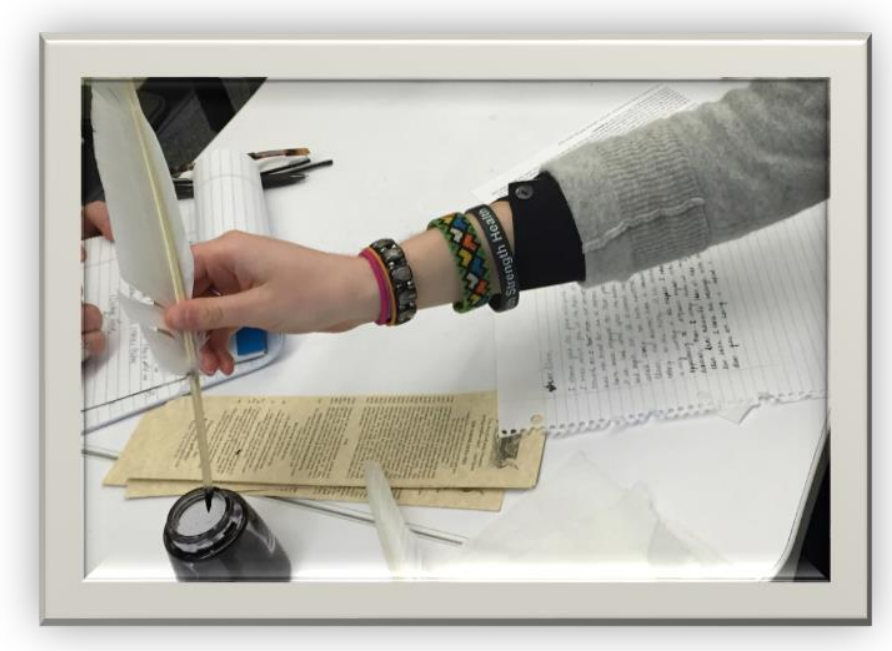




\section{Works Cited}

Austen, Jane. Sense and Sensibility. Edited by R.W. Chapman. $3^{\text {rd }}$ ed., Oxford UP, 1988.

Breashears, Caroline. "You're an Austen Heroine! Engaging Students with Past and Present." ABO: Interactive Journal for Women in the Arts, 1640-1830, vol. 4, no. 1, 2014, scholarcommons.usf.edu/abo/vol4/iss1/5/.

Hansen, Kathryn Strong. "Inviting Twenty-First Century Students to the Eighteenth-Century Party." ABO: Interactive Journal for Women in the Arts, 1640-1830, vol. 3, no.1, 2013, scholarcommons.usf.edu/abo/vol3/iss1/3/.

Krueger, Misty. "Mansfield Park Comes to Life: Teaching and Staging Elizabeth Inchbald's Lovers' Vows in an Austen Course." ABO: Interactive Journal for Women in the Arts, 1640-1830, vol. 5, no.1, 2015, scholarcommons.usf.edu/abo/vol5/iss1/2/.

Stam, Robert. "The Dialogics of Adaptation." Film Adaptation, Edited by James Naremore, Rutgers UP, 2000, pp. 54-76. 
Appendix A

Text! Tweet! Write!

\section{ENGL 364 Jane Austen: Then \& Now}

\section{Overview:}

You and your partner will take on the personas of two characters in Sense and Sensibility who experience communication issues or antagonisms of some sort and then communicate with each other via the assigned method as your chosen character. (Examples include Elinor and Marianne or Lucy Steele and Elinor).

\section{Exercise Objectives:}

- To explore how different forms of written communication produce different forms of meaning.

- To understand characterization and theme, then create your own interpretation from that understanding.

- To analyze and reflect upon perspective, purpose, medium, and audience.

- To consider what it takes to be an effective and responsible communicator.

\section{Guidelines and Instructions:}

1) Per your group's assigned method, text, tweet (tweeters: choose a hashtag and proceed accordingly. If you want to try taking on a larger group Twitter Chat, go for it! Just be sure each of you picks a distinct character), or hand write letters to each other as your characters for $\mathbf{1 5}$ minutes. Letter writers, be sure you give yourselves enough time to deliver your epistles to your partners.

2) Write an individual reflection (at least 5 sentences). Consider the purpose of your communication, the audience, the medium or means by which you communicated, and the themes of the novel you think you brought to bear on this exercise. Some questions to ponder just to get you going include: Who is the intended audience for your given form of communication and is the intended audience always also the actual audience? Explain. Did your method of communication increase or decrease intimacy between the characters? Why or why not? Did it create obstacles or hostilities or build bridges? Why? How? Did the characters reveal more or less of themselves with your format and audience considerations? Explain. What happens to your discourse when you communicate in a method to which you are accustomed or unaccustomed, as the case may be? Do factors such as age, race, class, and gender affect your method of communication? Why or why not? (5-10 minutes)

3) Be prepared to share your dialogues and your reflection with the entire class! 
ABO: Interactive Journal for Women in the Arts, 1640-1830, Vol. 7 [2017], Iss. 1, Art. 8 